\title{
The Influence of Convection Heat Transfers for Vertical Mini-Tubes Using Solvent Carbon Dioxide and Porous Media at Supercritical Pressure
}

\author{
Bilal J. Kkihlefa, Ameer A. Gaddoa $\mathbb{D}^{*}$, Ahmed H. Reja \\ Electromechanical Mechanical Engineering Department, University of Technology, Baghdad, Iraq. \\ *Corresponding author Email: ameer.a.jaddoa@uotechnology.edu.iq
}

\section{H I G H L I G H T S}

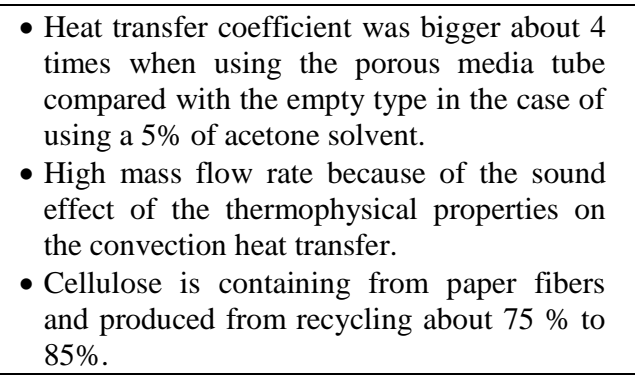

\section{A R T I C L E I N F O}

\begin{tabular}{l} 
Handling editor: Muhsin J. Jweeg \\
\hline Keywords: \\
Experimental Study \\
Heat Transfer \\
Vertical Mini-Tubes \\
Solvent $\mathrm{Co}_{2}$ \\
Porous Media \\
Supercritical Fluid \\
\hline
\end{tabular}

\author{
A B S T R A C T
}

Porous media and solvent $\mathrm{CO}_{2}$ at supercritical pressure were investigated experimentally to study the effect of convection heat transfer in vertical minitubes. Mini-tubes diameter $(5$ and $8 \mathrm{~mm}$ ) with medium porosity of 0.5 are proposed in experimental investigation. Experimental conditions consisted of bulk fluid, wall temperatures ranged from 33 to $55 \mathrm{oC}$, and 8 to $10 \mathrm{MPa}$ of pressure. Reynolds number, Mass flow rate, and heat flux were 1750 to 21000 , 0.5 to $4.5 \mathrm{Kg} / \mathrm{h}$, and $3.25 \times 104$ to $1.1 \times 105 \mathrm{~W} / \mathrm{m} 2$ respectively. Some chemical additives like Ethanol, Chloroform, Acetone, Dimethyl sulfoxide, and Methanol were considered. A special focus was dedicated to studying the influence of heat flux, inlet temperature, and mass flow rate at measured values of wall and fluid bulk temperatures, and coefficients of local heat transfer for mini-tubes and porous media. A higher effect was noticed on the convection heat transfer by buoyancy and properties of the thermophysical variable of solvent $\mathrm{CO} 2$ in minitube at vertical position. However, when these results were compared with the controls (empty tube) shoewn dramatically different results. Heat transfer coefficient was bigger about 4 times when using the porous media tube compared with the empty type in the case of using a $5 \%$ of acetone solvent.

\section{Introduction}

Transferring of the heat in supercritical fluid media nowadays is considering one of the most important technologies in heat transfer applications such as power plants especially when the fluid is water. When the conductors cooled by fluid to the closed critical points, it has called superconductivity. Many applications are using the supercritical fluids for the cooling blade of the gas turbine, cables of power transmission, elements of the supercomputer, etc. one of the famous ways to cool the military aircraft and rockets is fuel as a supercritical fluid. Many complex industrial applications suffer from catalytic breakdown due to the effects of coke as well as side reactions simultaneously. Therefore, the supercritical media being one of the important processes to avoid failure especially it contains many advantages such as no tension in the surface, no phase interaction, and no capillary influence. Also, these benefits lead to porous structure penetration as well as to heterogeneous catalytic regeneration and to avoid synthesis problems [1-4]. Moreover, supercritical fluids are considered as a way to increase the roughness of surfaces and analyze the free surface energy of the tissue when being not wet, and contact at high water higher than 150 [5]. Different fins in mini-tube by mixing convection heat transfer to supercritical carbon dioxide media experimentally was studied reference [6] indicated the influence of mass flow rate, the temperature of inlet and heat flux for miniature tube in addition to the factor of friction, improve efficiency, the correlation for Nusselt number and criteria of performance evaluation. Experimental verification has been done by Pei-Xue Jiang [7] in the vertical mini tube using supercritical $\mathrm{CO}_{2}$ to study the heat transfer by convection in addition to use porous media. S.M. Liao and T.S. Zhao [8] through 
the experimental data investigated experimentally the heat transfer by convection at horizontal and vertical mini tubes of supercritical $\mathrm{CO}_{2}$ and they worked on developing the correlations for Nusselt number to transfer the heat by convection. Examine the coefficient of heat transfer for supercritical $\mathrm{CO}_{2}$ has been done by Yoon et al. [9] experimentally for normal tubes during the cooling process. The tube diameter was more than $2 \mathrm{~mm}$ and the main suggestion was the correlations not forecasted the measured data. Nowadays, the importance of flowing the supercritical fluids in mini tubes raised significantly in many papers. In gas coolers of trans-critical $\mathrm{CO}_{2}$, Pettersen et al. [10] predicted the coefficient of heat transfer by Gnielinski's correlation. Liao and Zhao [11] used flowing of supercritical $\mathrm{CO}_{2}$ experimentally in theoretical estimation. Yoon et al. Jiang et al. [12] conducted the mini tube in the vertical position by studying the experimental and numerical heat transfer by convection for supercritical $\mathrm{CO}_{2}$. Asinari [13] tested the heat transfer by convection in the micro and mini tubes under the cooling process numerically with turbulent flowing the $\mathrm{CO}_{2}$ in supercritical pressure conditions. He et al. [14] suggested a correlation of heat transfer and inspected at low Reynolds number and turbulent flow the performance of combined tube (micro and mini) after proving that the large diameter of the tube cannot forecast the correlation in the mini tube. A review paper dealt with all correlation based on coefficient of heat transfer under supercritical $\mathrm{CO}_{2}$ has been conducted by Luisa F. Cabeza [15] in heat exchanger applications and discussed. The paper has taken into consideration many shapes and positions of tubes such as vertical and horizontal, straight and oblique, open and closed-loop circular pipe, many dimensions for the mini tube. The main conclusion for this paper was each geometry gave a different correlation and this field needs more study. Nasr et al. [16] used an experiment circular cylinder with a spherical particles package bed to study the forced heat transfer that led to enhance the Nusselt number compared with aluminum spheres up to 7 times. Both researchers [17] and [18] used the porous media technique for flat plate channels to investigate the heat transfer experimentally and the results showed that the proposed technique increased the coefficient of heat transfer from 5 to 10 times. Another notice was the increase due to the resistance in hydraulic at high fluxed of heat up to 4 × $107 \mathrm{~W} / \mathrm{m} 2$ when using single-phase water. The importance of viscosity should be taken into consideration at varying or temperature drop as argued Lai and Kulacki [19]. Jiang et al. [20] investigated the heat transfer behavior with porous media numerically at different parameters which are; buoyancy, the thermal conductivity of solid particles, variable properties, and particle diameter. At very high heat fluxes, one cannot neglect the effect of buoyancy in addition to affecting the variable properties and supercritical pressure on heat transfer. Finally, the current work studied the characteristics of heat transfer and the performance of heat transfer in the mini vertical tube and porous media under supercritical fluid modification solvent to meet this field at many scales. The scaling principle behavior of integral heat transfer will be studied for pipe in the vertical position to investigate the system performance with taking into consideration the flowing of supercritical $\mathrm{CO} 2$ and compare the experimental results with heat flux uniform distribution.

\section{Experimental work}

The experimental setup was done in this work with integrated measurement devices for studying the heat transfer behavior with porous media and $\mathrm{CO} 2$ at forwarding fluid flow in vertical mini-tube as shown in Figure 1(a,b,c).

The system consisted of $\mathrm{CO}_{2}$ cylinder with pure carbon of $99.7 \%$, compressed Ammonia gas for the refrigerant system which the gas firstly heats by coil after compressing it by the compressor, then the gas condenses and converts to from orange color to blue dark color as a fluid by evaporating pressure. The expansion valve uses to pass the gas from high pressure to low pressure by a small hole and reaches the boiling degree. Then the liquid transfer to the lite blue as gas again due to evaporation and the temperature of vaporized ammonia value up to $-27^{\circ} \mathrm{C}$. The cycle will be repeated inside the system by compressing it and heat again. Based on the ethylene glycol as a coolant has high efficiency, low cost, reduce and control the temperature in bi-directions, high thermal capacity and not as a side effect on the environment, it's proposed to be the coolant gas which is considered one of the most important parts in the system. Other advantages of the coolant gas are not harmful to the system, which means keep the system against corrosion, an Inactive chemical element, increases the system age, insulates the electricity in some times, and not need to maintain it for a long time. To control the flow in bi-direction, a valve-type standard needle has been used especially for high pressure that carries up to 200 bar and withstands temperatures from - 10 to $200{ }^{\circ} \mathrm{C}$. Also, the valve opens fully less than $31 / 2$ cycle. To carry the high pressure and temperature, tools (springs, handle that used to prevent the gas leakage, and fixed screws) in this work made from stainless steel. A heavy-duty two pieces have been utilized to make the stem adaptive and reliable. In addition, packing gland/body thread employed for vibrating resistance with weep hole double side to easily discover the system leakage. One of the important measurement systems used in this work is manometers type Bourdon (PG23HP) made in Germany that used for pressure measuring. The characteristics of the manometer are measuring the high pressure up to 500 bar with an accuracy of $1 \%$. Many procedures have been taken into consideration to protect the system and components from failure and leakage, one of these procedures is used from the front side of the actuator. The reliability of instrument measurement has been taken into consideration to make sure that the instrument working well without leakage and compatible with the work environment. Therefore, the static and dynamic pressure is measured in bi-direction flow. Also, mass flow rate type TSI of 5210-7 with accuracy $2 \%$ utilized in this work that has a wide measuring range from 0-30 L/ min to measure the differential pressure between two points in one line.

Many sensors have been built inside the system such as pressure and temperature sensors to get accurate data. So, total and absolute pressure and temperature have been measured, to measure the volume by totalizer measurement that depends on temperature and pressure tigers. All data have been recorded by the data logger and displayed four reading timely and directly for gas volume using touchable and cooler screen, temperatures, and pressures for supercritical $\mathrm{CO}_{2}$ system. On the other hand, the FLO-Sight program has been used after installing and setting it to operate the gas flow meter by computer using couple. An analogy linear sensor type $\mathrm{Lm} 35$ was used to measure the temperatures set by each $1{ }^{\circ} \mathrm{C}$ equal to $10 \mathrm{mv}$. Moreover, thermocouples type $\mathrm{k}$ with linear sensitivity of $41 \mu \mathrm{V} /{ }^{\circ} \mathrm{C}$ also used that made from chrome-alumel to measure the temperature 
reading from -200 to $1350{ }^{\circ} \mathrm{C}$ for high-temperature readings which depends on the thermoelectric concept (variable resistances). To derive the control process, the microcontroller device used in this work is Arduino Uno that provides an input voltage from 0 to $5 \mathrm{~V}$ and stores $0-1023$ as a 10 bit. But due to some sensors depends on the changing in resistance on semiconductors; some difference in reading has been noticed. The filter housing that used in this paper is made from carbon steel to filter the $\mathrm{CO}_{2}$. This filter can resist pressure up to 100 bars. The wires have been covered in this work by the Nichrome heating element strips with length 10 m that composited from $20 \%$ of Chromium and $80 \%$ of Nickel to protect the wires during high temperatures and pressures from breaking or burning. The other advantage of the Nichrome heating element is to resist the oxidation by creating the chromium oxide layer at the first time of heating in addition to carries the power of about $1500 \mathrm{~W}$ and current about $6.8 \mathrm{~A}$. A Variac device is used to provide an adequate voltage which is an AC transformer 520T-10- $14 \mathrm{lbs}$. this device can provide an output voltage from 0 to $130 \mathrm{~V}$ and output current of $10 \mathrm{~A}$ and consumes input voltage of $110 \mathrm{~V}$ with the number of connection pins of 3 and output sockets of 3 . To insulate the system thermally, Cellulose has been utilized which is considering a friend to the environment and high insulation performance. Cellulose is containing from paper fibers and produced from recycling about $75 \%$ to $85 \%$. The remained percentage (15\%) is made for boric acid or ammonium sulfate as a fire retardant due to it doesn't have oxygen and all composition of Cellulose are compressed. Therefore, the type of material uses for fire resistance and decrease fire damage. The test section has manufactured from pure copper with atomic number 29 about $99.5 \%$ in addition to other characteristics such as high conductivity for electricity, high conductivity for thermal high, cheap and easy to configuration due to its malleable and ductile. The uncovered surface cooler of the copper has a pinkish-orange color. Finally, pure copper was a successful material and widely uses in different applications like marine equipment, manufacturing devices, coins, etc. therefore, it's proposed in the experimental work to manufacture the test section.

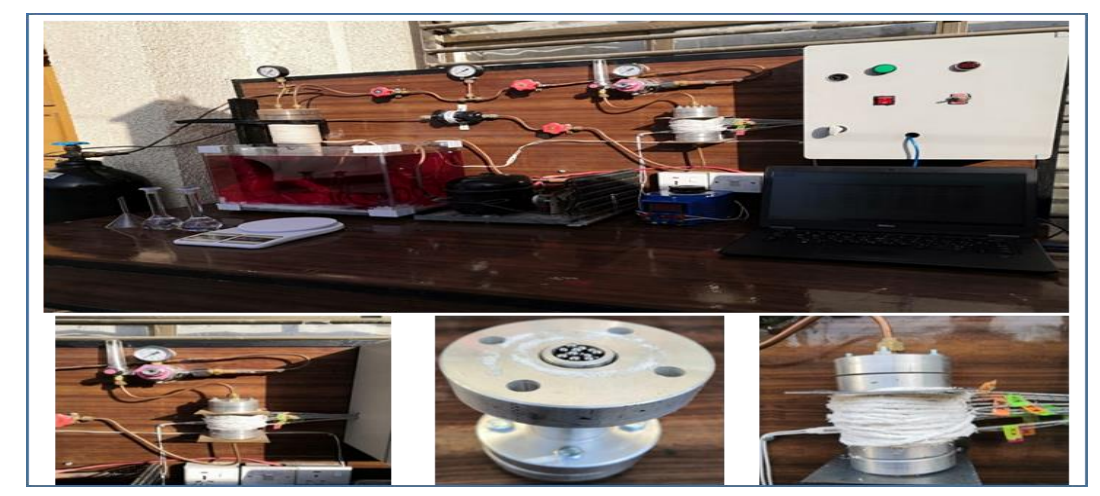

(a)

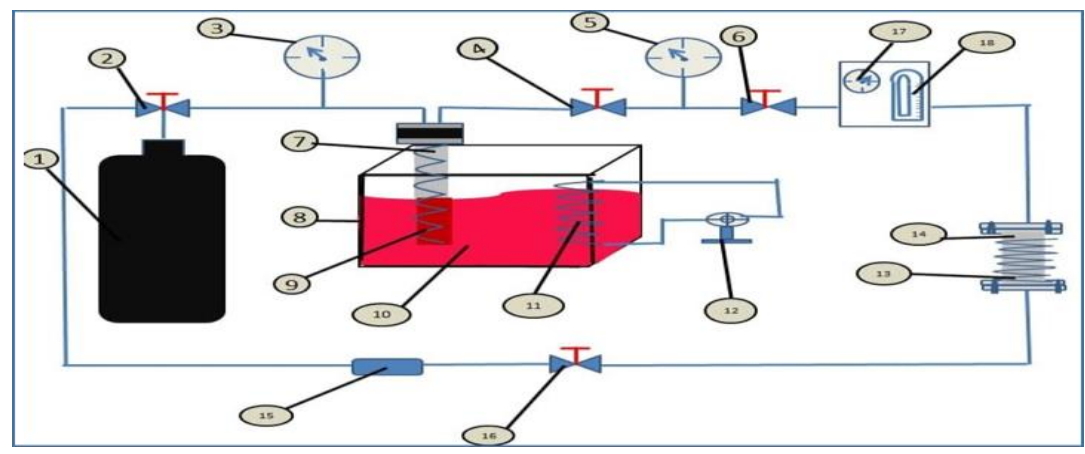

(b)

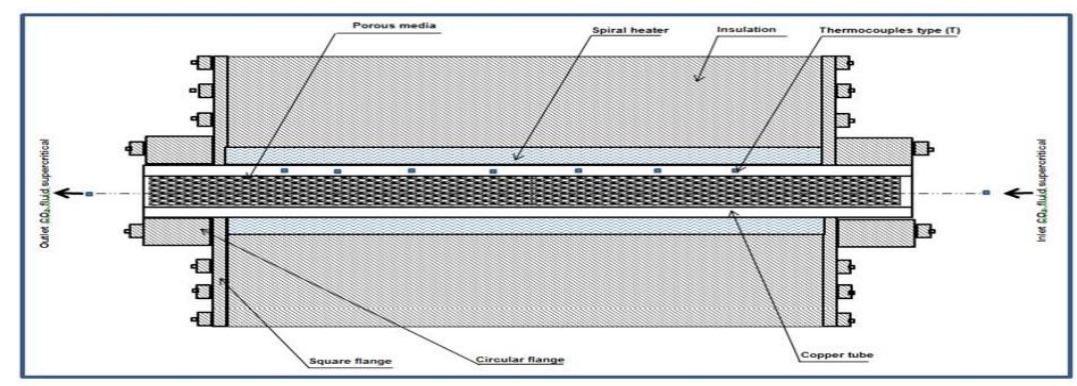

(c)

Figure 1: (a)Experimental setup of supercritical carbon dioxide (Photo) 
(b) Schematic Experimental of test rig 1- cylinder $\mathrm{CO}_{2}, 2,4,6,16$ expansion valve high pressure, 5,3Manometr high pressure, 17,18 flow meter high pressure,7,8,9,10,11,12 refrigeration system ,14,13 test section, $15 \mathrm{CO}_{2}$ filter. (c): Front View Test Section of Experimental setup

To calculate the local tube of inter-surface temperature [24], the equation below has used.

$$
\mathrm{T}_{\mathrm{wi}}=\mathrm{T}_{\mathrm{wo}}+\left(\frac{\mathrm{q}}{16 \mathrm{k}}\right)\left(\mathrm{d}_{\mathrm{o}}-\mathrm{d}_{\mathrm{i}}\right)^{2}+\left(\frac{\mathrm{q}}{8 \mathrm{k}} \mathrm{d}_{\mathrm{i}}^{2}\right) \ln
$$

Eq. (2) has used to calculate the coefficient of local heat transfer

$$
h_{x}=\frac{q}{\left(T_{w i}-T_{f}\right)(x)}
$$

While Eq. (2) was used at each axial location to calculate the Nusselt number.

$$
\mathrm{Nu}=\frac{\mathrm{h}_{\mathrm{x}} \mathrm{d}}{\mathrm{K}_{\mathrm{f}}}
$$

To calculate the enthalpy of local bulk fluid, Eq. (4) has been used and to calculate the temperature of local bulk fluid later.

$$
h_{f b}=h_{f o}+\frac{\pi q d x}{m^{\circ}}
$$

The mean heat transfer coefficient was calculated as:

$$
h=\frac{q}{T_{w i}-T_{f}}
$$

Eq. (6) uses to calculate the mean Nusselt number in the tubes

$$
\mathrm{Nu}=\frac{\mathrm{hd}}{\mathrm{K}_{\mathrm{f}}}
$$

While the temperature of all local walls has calculated based on calculating the heat transfer surface mean temperature as shown below.

$$
\mathrm{T}_{\mathrm{m}}=\sum_{\mathrm{i}=1}^{\mathrm{n}}\left(\mathrm{T}_{\mathrm{wi}} \Delta \mathrm{x}\right) / \mathrm{L}
$$

Finally, to estimate the Reynolds number, the equation below has used.

$$
\operatorname{Re}=\frac{4 \mathrm{~m}}{\mathrm{~d} \mu \pi}
$$

\section{Experimental validation}

Many forms of comparisons have been made in this study such as comparing the heat transfer by convection of empty tube and with established correlations. Also, the comparison consisted of evaluating the system with many formulas by Grigoriev [23] and Krasnoshchekov , Protopopov [21,22] for the empty tube by estimate the values of Nusselt numbers for in transition and turbulent heat transfer by convection.

$$
\frac{N u_{o}}{N u\left(\frac{x}{d}\right)}=\frac{1}{E_{1} E_{2}\left(\frac{x}{d}\right)}
$$

Where:

$$
\begin{aligned}
& E_{1}=\operatorname{Re}_{f}^{-0.15} \operatorname{Pr}_{f}^{-0.4}\left(\frac{x}{d}\right)^{-0.6}+1 e^{-i \omega t-0.3 R e_{f}^{-0.1}\left(\frac{x}{d}\right)} \\
& E_{1}=\left(c_{p} / c_{p b}\right)^{n}\left(\rho_{w} / \rho_{b}\right)^{n} \\
& c_{p}=\int_{T_{b}}^{T_{w}} \frac{c_{p}}{T_{W}-T_{b}} d T=\frac{h_{w}-h_{b}}{T_{w}-T_{b}}
\end{aligned}
$$

\section{Convection heat transfer in the Empty mini-tube with pure $\mathrm{CO}_{2}$}

The effect of coefficient for local heat transfer and temperature have been presented in Figures $2(a, b)$ and $3(a, b)$ in addition to present the distribution of wall temperature and fluids. Based on Figure 2(a,b), a small variation in the temperature of fluids has been noticed due to a small heat flux. Also, the temperature of pseudo-critical was larger than the temperature of 
bulk fluid when the temperature of the inlet was less than it (temperatures of inlet equal to 33,38 , and $40{ }^{\circ} \mathrm{C}$ ). Moreover, a few effects were noticed on the coefficient of local heat transfer by the temperature of the inlet due to a few differences between the temperature of bulk fluid and temperatures of the wall. The current experimental outcomes when the temperatures of inlet equal to 33,38 , and $40{ }^{\circ} \mathrm{C}$ were pretty closed compared with the estimated outcomes Equation (9). But, the temperatures of the wall throughout the tube were noticed higher than the Tpc $\left(43{ }^{\circ} \mathrm{C}\right)$ due to the temperature of pseudo-critical lower than $52{ }^{\circ} \mathrm{C}$ of temperature inlet. The coefficient of local heat transfer was noticed lower than those when the temperature of the inlet lower than Tpc (about 2-fold). The great similarity of the results of Equation (9) and the temperature of the inlet at $52{ }^{\circ} \mathrm{C}$ also observed. According to Fig. 3(a,b), the fluxes of heat for the data were larger due to the larger variations of fluid temperatures compared with Fig. 2. $(\mathrm{a}, \mathrm{b})$ When $\mathrm{T}_{\mathrm{pc}}$ larger than the temperatures of the inlet, the outcomes of data for these various temperatures of the inlet were similar. On the other point of view, the outcomes of experimental work greatly vary from the estimated correlation outcomes in equation (9) due to the high difference between the temperature of the bulk fluid and the temperature of the wall. When the $\mathrm{T}_{\mathrm{pc}}$ lower than the $49{ }^{\circ} \mathrm{C}$ as a temperature of the inlet, Tpc also lower than the temperatures of the wall and the temperature fluid bulk which is $43{ }^{\circ} \mathrm{C}$. The coefficient of local heat transfer was noticed lower than those when the temperature of inlet $43{ }^{\circ} \mathrm{C}$ lower than $\mathrm{T}_{\mathrm{pc}}$. The experimental results for high inlet temperatures were similar to the results calculated using Eq. (9). It can be seen a pretty accurate for Eq. (9) when the Tpc larger than the temperatures of fluid bulk for Figures 2(a,b) and 3(a,b). Also, a small difference between the temperatures of bulk fluid and the temperature of the wall can be seen at large rates of mass flow and low fluxes of heat. When the Tpc lower than the temperatures of fluid bulk, a large difference can be seen between the temperatures of bulk fluid and the temperature of the wall. However, when the Tpc larger than the temperatures of fluid bulk and the large differences between the temperatures of bulk fluid and temperature of the wall at small flow rates or large heat fluxes, Eq. (9) cannot forecast precisely the experimental data.

Figure 4(a,b) shows the effect of different rates of mass flow with the temperatures of bulk fluid, temperatures of the wall, and coefficient of the local heat transfer in the mini tube. It can show that the values of the temperatures of bulk fluid and temperature of wall lower than the Tpc $(43 \mathrm{oC})$ and the fluxes of heat is small. The experimental outcomes at different rates of mass flow are compatible with correlation outcomes in equation (9). It also notices that the large rates of mass flow don't mean intensive heat transfer by convection at supercritical pressures. According to Fig 3 at super-critical pressures, curve 4 higher rates of mass flow compared with curve 3 despite the coefficient of heat transfer for curve 4 lower than curve 3 . Thus, the strong and main affection of the heat transfer by convection was the temperature of the inlet, the flux of heat, and the rate of mass flow.

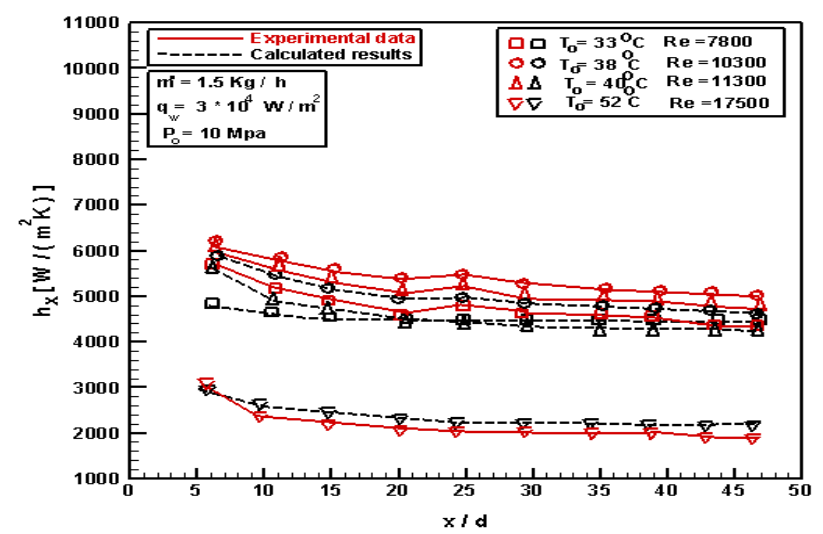

(a)

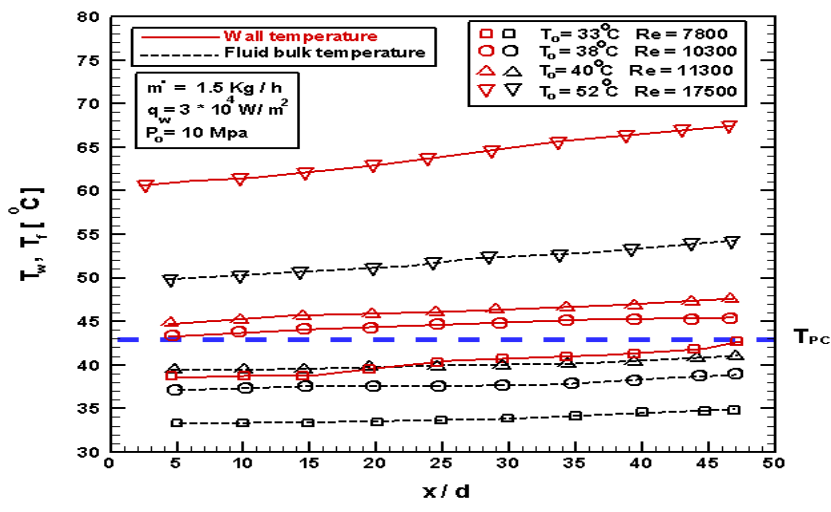

(b)

Figure 2: (a) Effect Local heat transfer coefficients for different inlet temperatures

(b) Effect fluid and wall temperatures for different inlet temperatures

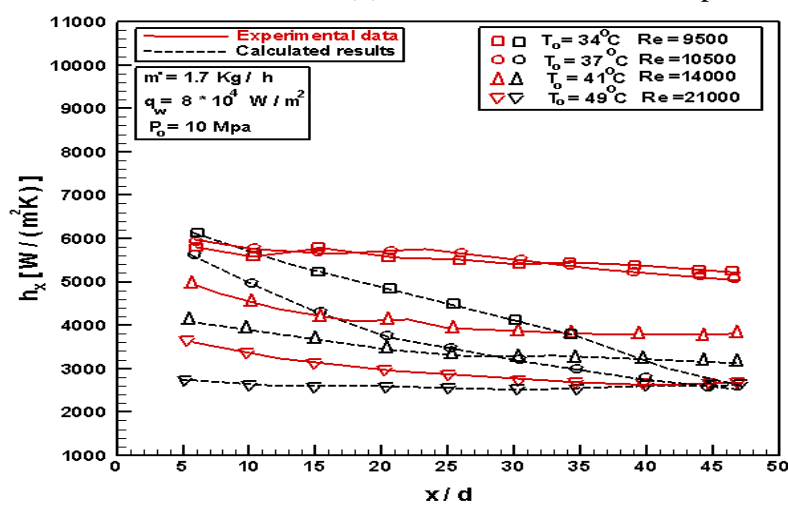

(a)

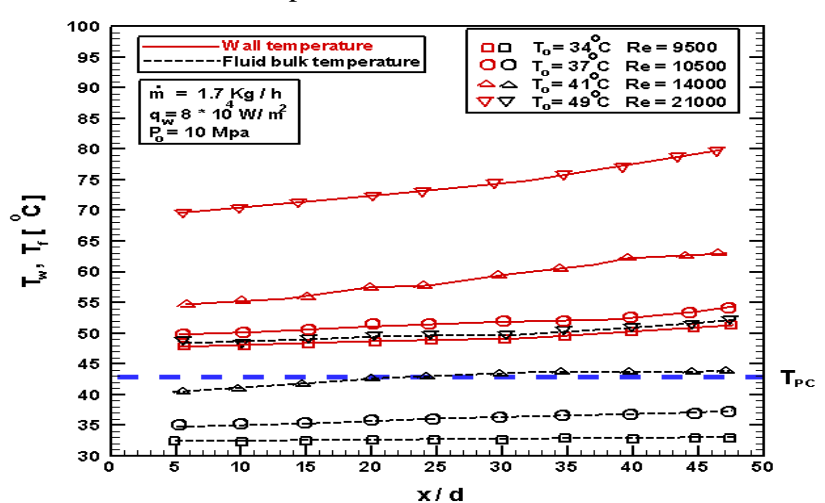

(b)

Figure 3: (a) Effect Local heat transfer coefficients for different inlet temperatures

(b) Effect fluid and wall temperatures for different inlet temperatures 


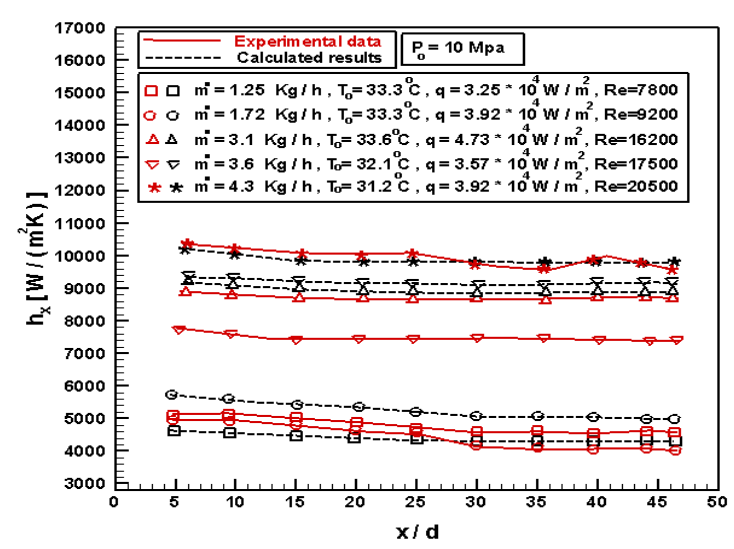

(a)

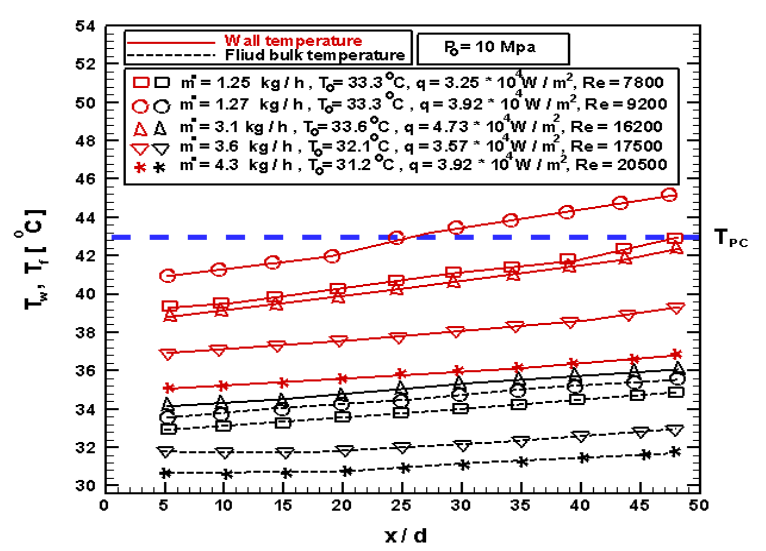

(b)

Figure 4: (a) Effect Local heat transfer coefficients for different mass flow rates

(b) Effect fluid and wall temperatures for different mass flow rates

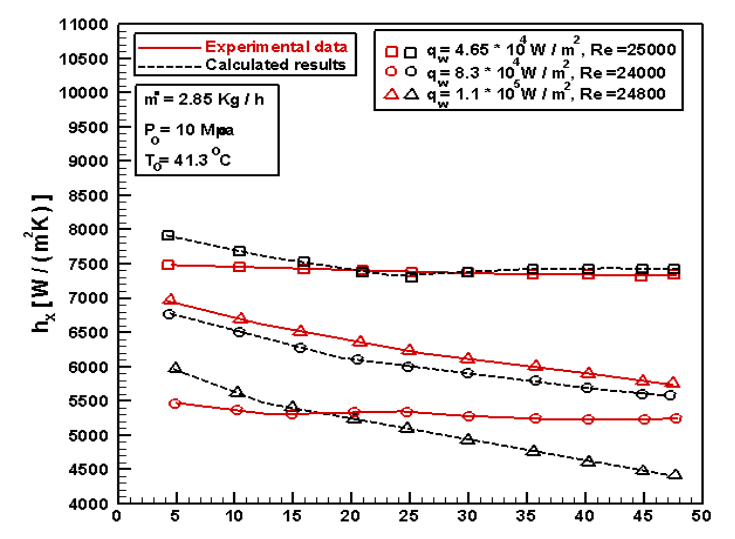

(a) $)^{x / d}$

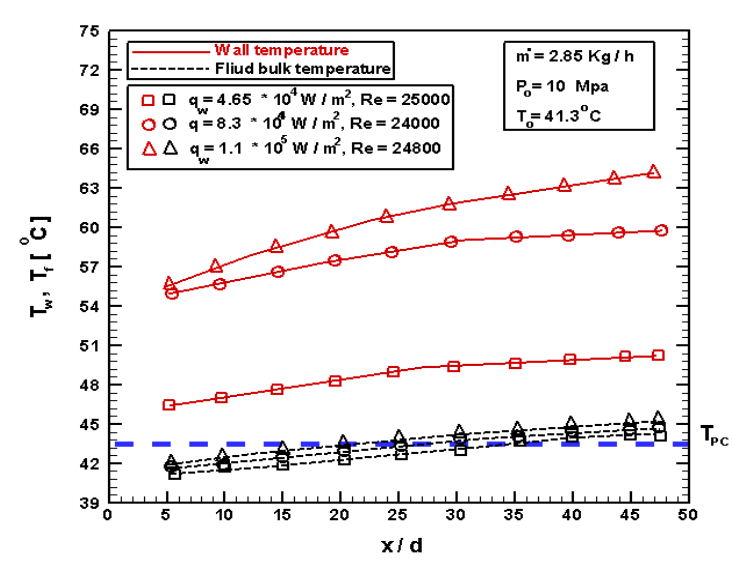

(b)

Figure 5: (a) Effect Local heat transfer coefficients for different heat flux

(b) Effect fluid and wall temperatures for different heat flux

Figure 5(a,b) shows the flux of heat effect on the temperatures of bulk fluid, temperatures of the wall, and coefficient of the local heat transfer in the mini tube. For different fluxes of heat, the coefficients of heat transfer also very different at the same temperature of inlet and rate of mass low because of the different thermos-physical properties for super-critical conditions. When the fluxes of heat are highest and equal to $1.1 \times 105 \mathrm{~W} / \mathrm{m} 2$ and $8.3 \times 104 \mathrm{~W} / \mathrm{m} 2$, the correlation and experimental coefficient of heat transfer be lower than those when the flux of heat equal to $4.65 \times 104 \mathrm{~W} / \mathrm{m} 2$. Due to the same reason above despite the coefficients of heat transfer measured experimentally at the flux of heat equal to $8.3 \times 104 \mathrm{~W} / \mathrm{m} 2$ are lower than those when the flux of heat equal to $1.1 \times 105 \mathrm{~W} / \mathrm{m} 2$. Also, the outcomes of correlation for the flux of heat equal to $8.3 \times 104 \mathrm{~W} / \mathrm{m} 2$ and coefficient of heat transfer were lower than those when the flux of heat equal to $1.1 \times 105 \mathrm{~W} / \mathrm{m} 2$.

\section{Convection heat transfer in a porous tube with pure $\mathrm{CO}_{2}$}

This section presents and discusses the experimental work results to evaluate the system performance based on supercritical $\mathrm{CO} 2$ and porous media of 0.5 porosity and $8 \mathrm{~mm}$ for tube diameter in the vertical position on the heat transfer characteristics. Figures 2 to 4 show the coefficient of heat transfer with measured temperature of the wall for solid symbols and temperature of bulk fluid for hollow symbols. Figure. 6 presents the inlet temperature effect on the coefficient of local heat transfer in addition to present the temperatures of bulk fluid and wall distribution. At pressure $9 \mathrm{MPa}$, the temperature of pseudo-critical was $38 \mathrm{oC}$ for $\mathrm{CO} 2$. For the same pressure in addition to the same heat flux, mass flow rate, one of the important notices the significant effect of inlet temperature on heat transfer. The reason behind that the variable thermophysical properties. When Tpc equal to $42 \mathrm{oC}$ and lower than the inlet temperature, the same behavior (greater than Tpc) along the tube for temperatures of the wall. When the Tpc larger than the inlet temperature or around it, a lower value of about 4-fold was for the coefficient of heat transfer.

Heat flux effect on the coefficient of heat transfer and temperatures of wall and fluid bulk have presented in Figure. 7 using porous media and supercritical CO2. When the heat flux $(2600 \mathrm{~W} / \mathrm{m} 2)$ below, the coefficients of heat transfer also being low and opposite. Another statement is that an increase in the coefficient of heat transfer leads to an increase in the temperature of the heat flux. The reason for that is using of the porous media with the acceleration inflow when the temperature of pseudocritical closed to fluid bulk temperature and lower than the temperature of the wall. All the previous results have been noticed when the range of the Reynolds numbers between 2300 to 3300 and a little influence has been noticed for turbulence on the fluid flow acceleration at small size (0.5) for porosity. On the other hand, when the heat flux be highest at $29000 \mathrm{~W} / \mathrm{m} 2$, the 
coefficient of heat transfer be less compared with the case of the lowest heat flux at $16000 \mathrm{~W} / \mathrm{m} 2$. Where, it may be considering that the thermophysical properties were the main reason for the system behavior in addition that the temperatures of wall and fluid bulk were much larger than Tpc with the heat flux of $(29000 \mathrm{~W} / \mathrm{m} 2)$.

Mass flow rate effect on the coefficient of heat transfer and temperatures of wall and fluid bulk have presented in Figure. 8 using porous media and supercritical CO2. It has been observed that the heat transfer always has not an intensity compared with the high mass flow rate because of the sound effect of the thermophysical properties on the convection heat transfer.
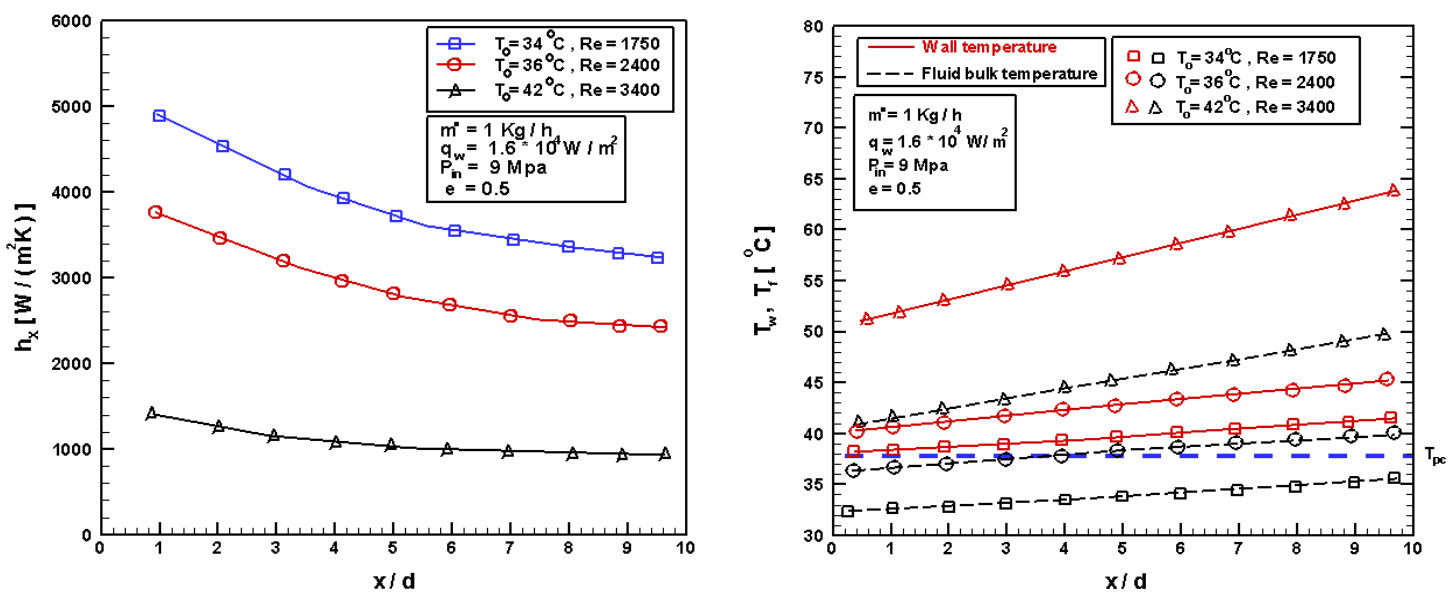

Figure 6: Coefficients of heat transfer distribution with temperatures of wall and bulk fluid at different inlet temperature
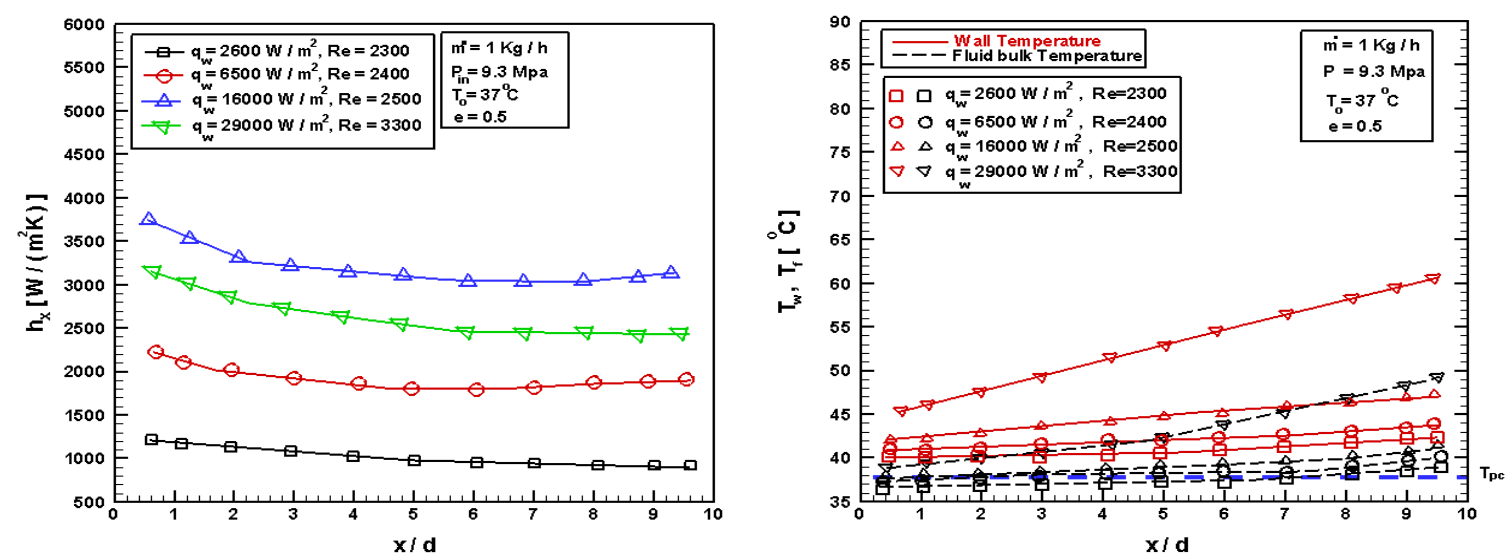

Figure 7: Coefficients of heat transfer distribution with temperatures of wall and bulk fluid at different heat fluxes
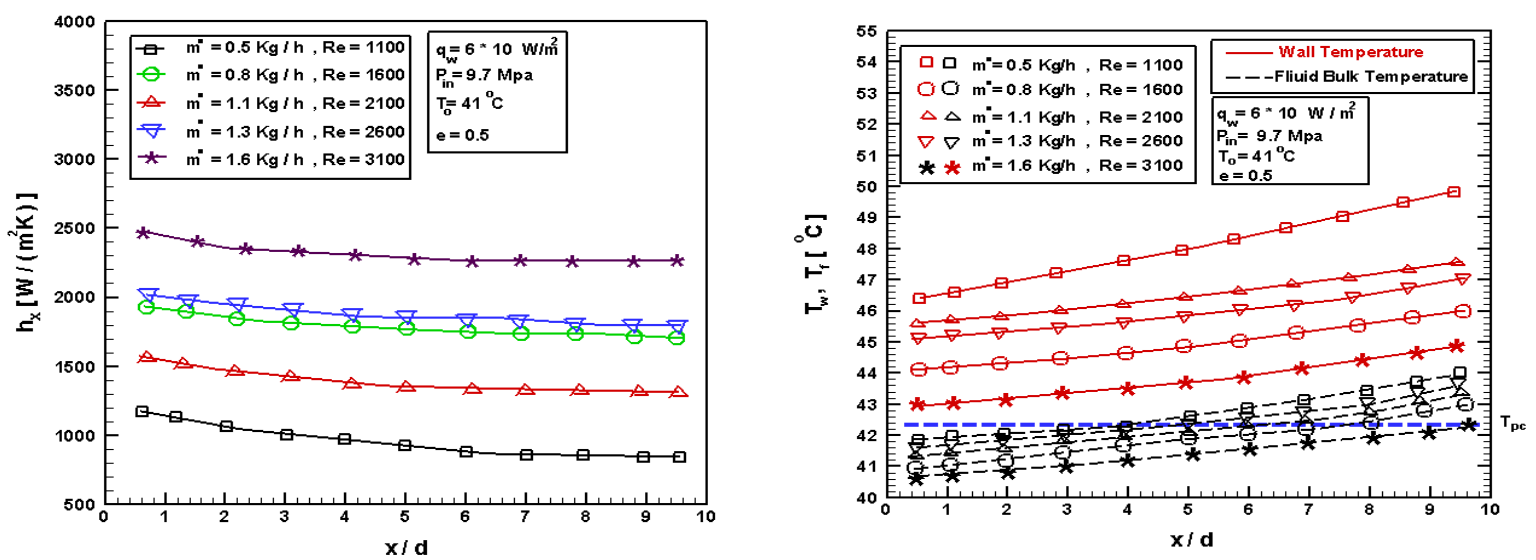

Figure 8: Coefficients of heat transfer distribution with temperatures of wall and bulk fluid at different mass flow rates 


\section{Convection heat transfer in a porous tube with pure $\mathrm{CO}_{2}+\mathrm{SOLVENT}$}

The environmentally benign nature of carbon dioxide comes from its very stable molecular bonds, which in turn do not provide high polarity. A carbon dioxide molecule has only a weak quadrupole moment, due to minor charge separation on oxygen and carbon atoms. Hence, the molecular interaction with most polar and heavy substances of interest is minor, providing only a weak solvent power. If needed, a small amount of cosolvent (also termed as entrainer or modifier) is added to enhance polarity and affinity with solutes. In many applications, however, the design limitation is the solubility of the substance in supercritical carbon dioxide. Therefore, the solubility data are essential both for the initial feasibility study and final process design [1-6]. The study focused on the following polar additives: Acetone, Ethanol, Methanol, Chloroform, and Dimethyl sulfoxide (DMSO). The highest degree of heat transfer is provided when using Acetone as a co-solvent. It is this cosolvent that has the highest polarity (4.05 Debye) in comparison with the rest of the substances considered (ethanol - 2.13 Debye, methanol - 1.71 Debye, chloroform - 1.14 Debye, Dimethyl sulfoxide- 1.12 Debye), which and allows the most complete extraction of polar compounds [24]. Based on the above, in the second series of experiments, a study was carried out to establish the optimal nature of the cosolvent and the most appropriate value of its concentration. The best heat transfer was at a concentration of $5 \%$ acetone the results of which are shown in Figure 9.

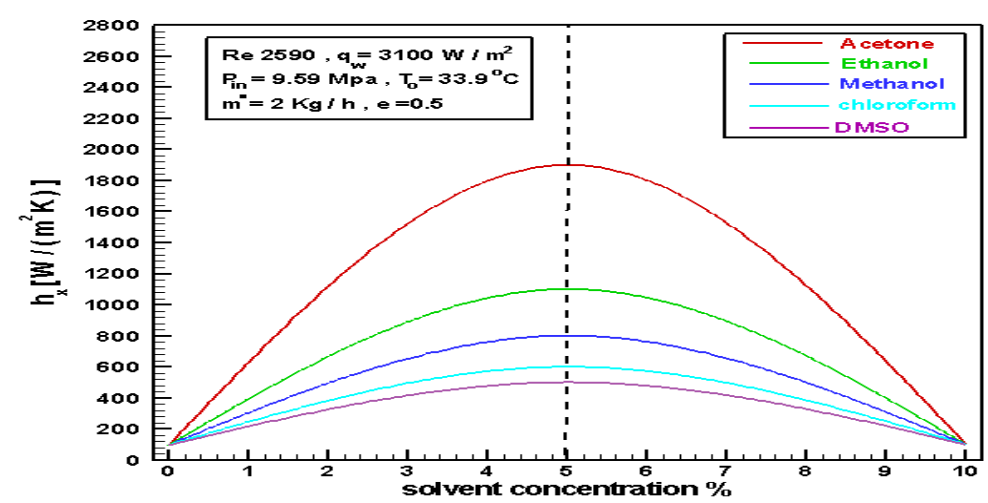

Figure 9: Variable of heat transfer coefficient with Solvent concentration
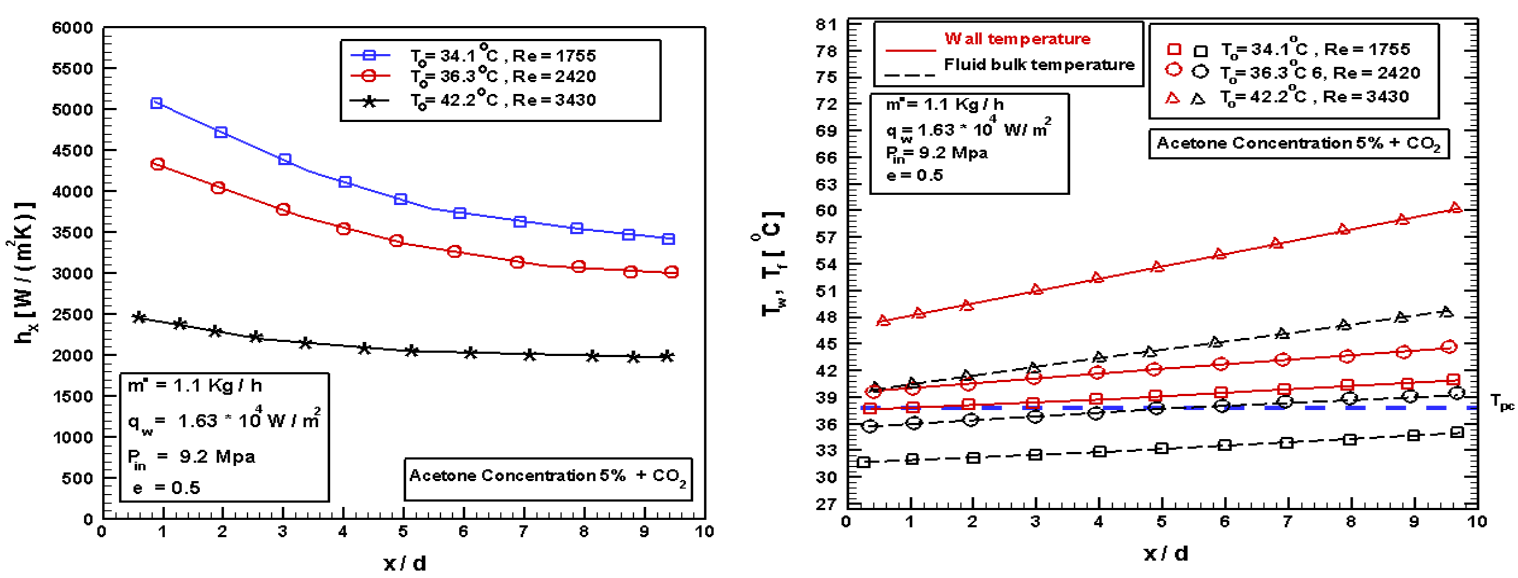

Figure 10: Coefficients of heat transfer distribution with temperatures of wall and bulk fluid at different inlet temperature
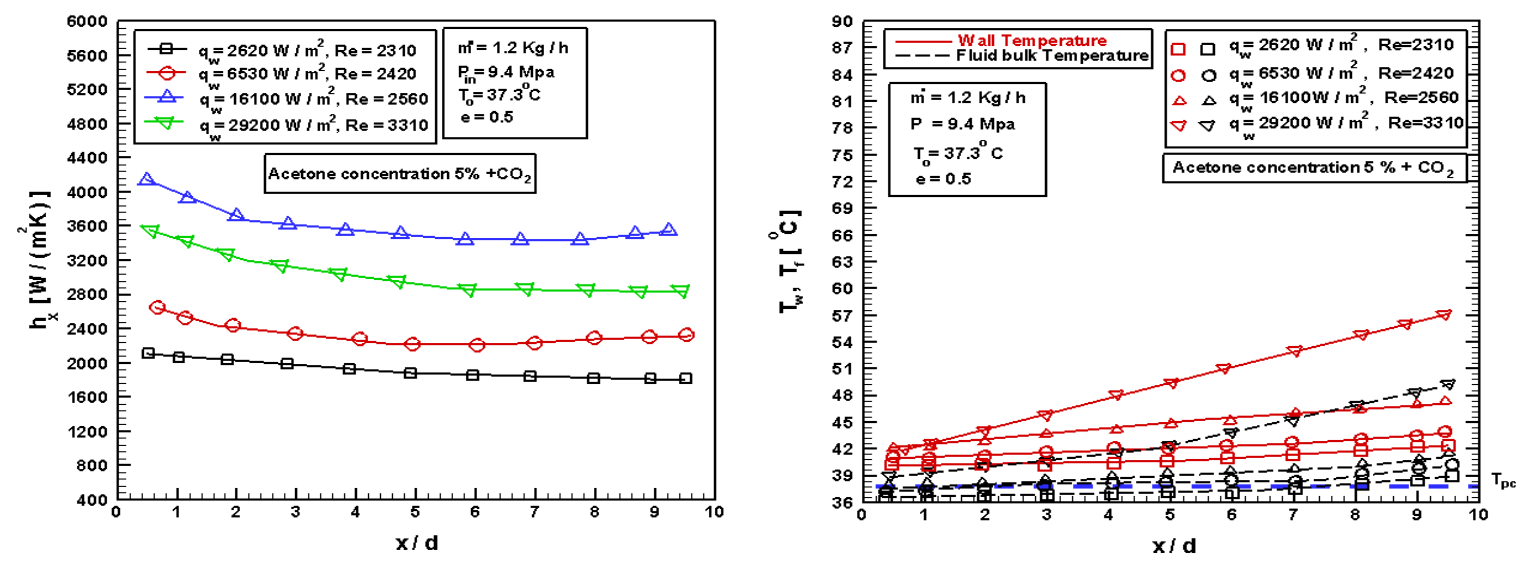

Figure 11: Coefficients of heat transfer distribution with temperatures of wall and bulk fluid at different heat fluxes 

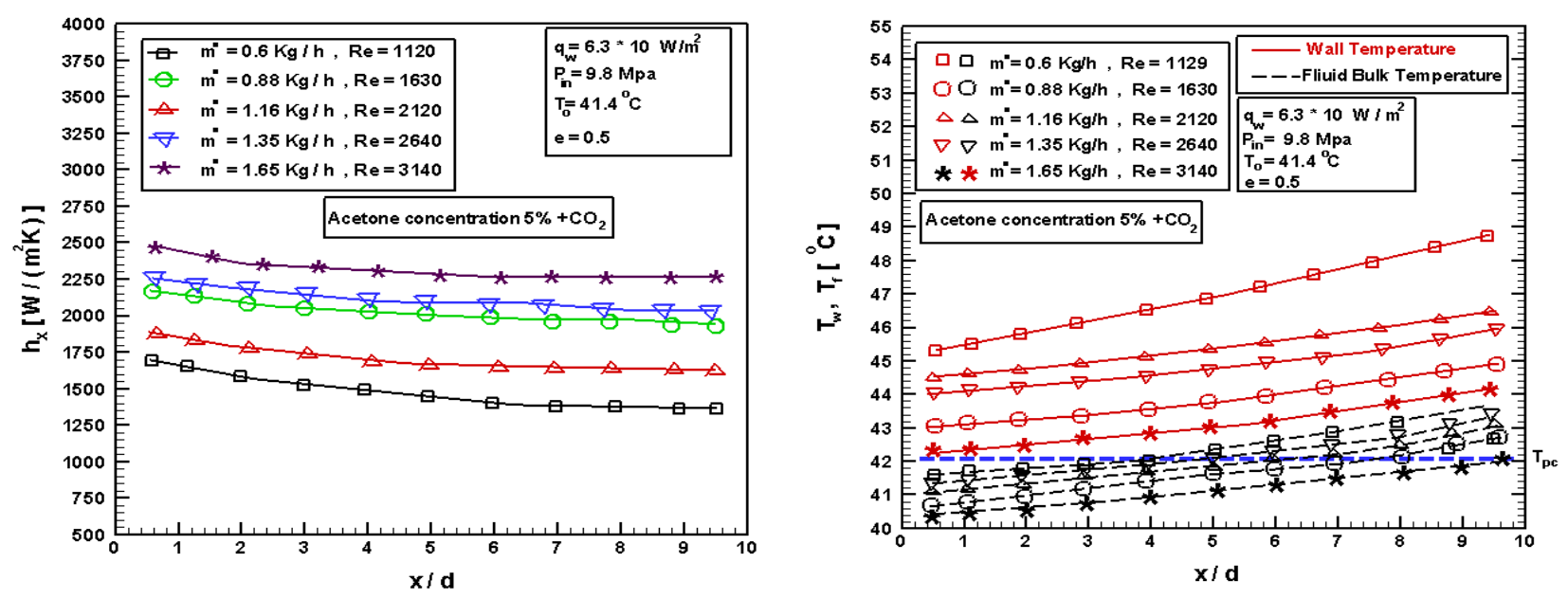

Figure 12: Coefficients of heat transfer distribution with temperatures of wall and bulk fluid at different mass flow rates.
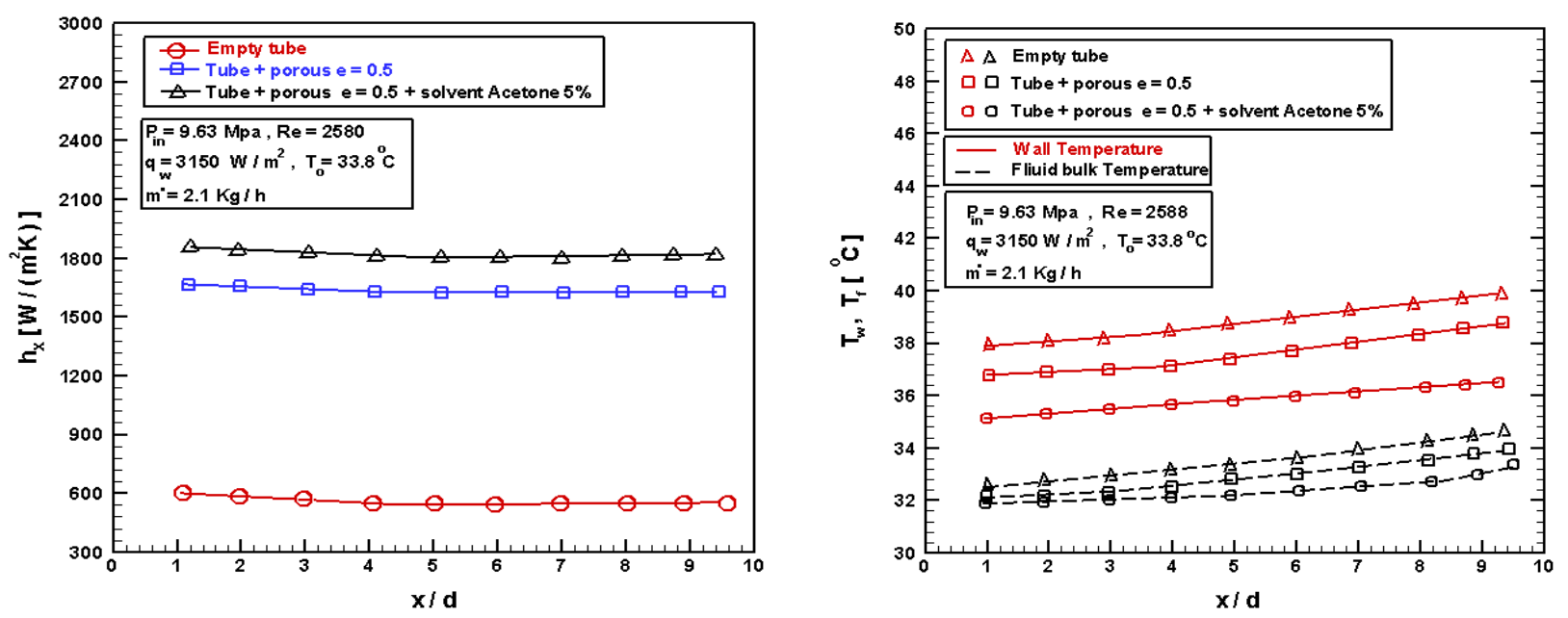

Figure 13: Comparison of local heat transfer coefficients and fluid and wall temperatures in a porous tube modification solvent acetone with $5 \%$ concentration and an empty tube.

Figures 10-12 present the experimental results for the local heat transfer coefficients and wall and fluid bulk temperatures for convection heat transfer of $\mathrm{CO} 2$ at supercritical pressures in the $8 \mathrm{~mm}$ ID porous tube and 0.5 porosity with adding a concentration of acetone $5 \%$.

Figure 13 compares the local heat transfer coefficients and the wall and fluid bulk temperatures in the porous tube modification solvent acetone with $5 \%$ concentration and the empty tube for the same $5 \mathrm{~mm}$ diameter. For those conditions, the local heat transfer coefficients in the porous tube modification solvent acetone with $5 \%$ concentration are about four times those in the empty tube.

\section{Conclusion}

A porous media with solvent $\mathrm{CO}_{2}$ has been proposed to investigate the convection heat transfer performance at supercritical pressure in mini-tubes as well as a comparison of the results with empty tubes experimentally. After measuring the different parameters such as fluid bulk and wall temperatures, properties of the thermophysical variable and coefficient of heat transfer have been conducted. Many conclusions can be obtained in this work. In the beginning, convection heat transfer is not always more intensive for larger mass flow rates in porous and empty tubes. Also, a strong effect has been noticed on the convection heat transfer due to mass flow rate, inlet temperature, and heat flux. On the other hand, for both cases (with and without porous media), the coefficient of heat transfer be affected based on the relationship between inlet temperature and Tpc. In detail, if the inlet temperature being much higher than the Tpc, the coefficient of heat transfer is a little lower than the case if the inlet temperature is lower than the Tpc. In another conclusion, similar heat transfer coefficients have been observed between experimental results and correlation outcomes in Equation 9 in the case of small heat flux. In addition, heat transfer coefficients were few differences between high and low heat fluxes for the tube with porous media, but different behavior for the empty tube. Increase the heat flux with porous media case led to increasing the heat transfer coefficient due to fluid flow acceleration. A complex effect has been observed for heat flux especially at the high value on coefficient heat transfer and the reason for this is attributed to thermophysical properties variation. In an empty tube, the buoyancy was increased at high heat 
fluxes and led to a decrease in the heat transfer turbulent. heat transfer coefficient was bigger about 4 times (20\%) when using the porous media tube compared with the empty type in case of using a 5\% of acetone solvent. Finally, these results can be verified numerically to enhance the model physically.

Nomenclature

\begin{tabular}{|llll|}
\hline$c_{p}$ & specific heat at constant pressure $[\mathrm{J} /(\mathrm{kg} \mathrm{K})]$ & $u$ & velocity $(\mathrm{m} / \mathrm{s})$ \\
$d$ & diameter of tube $(\mathrm{m})$ & $x$ & axial coordinate $(\mathrm{m})$ \\
$g$ & acceleration gravitational $\left(\mathrm{m} / \mathrm{s}^{2}\right)$ & & \\
$m$ & flow rate mass $(\mathrm{kg} / \mathrm{s})$ & Greek symbols & \\
$h$ & coefficient of mean heat transfer $\left(\mathrm{W} /\left(\mathrm{m}^{2}{ }^{\circ} \mathrm{C}\right)\right)$ & $\rho$ & density $\left(\mathrm{kg} / \mathrm{m}^{3}\right)$ \\
$h_{f, o, b}$ & bulk and inlet fluid specific enthalpy $(\mathrm{J} / \mathrm{kg})$ & $\mu$ & viscosity dynamic $(\mathrm{kg} /(\mathrm{m} \mathrm{s}))$ \\
$N u$ & Nusselt number $\frac{\mathrm{h}_{\mathrm{x}} \mathrm{d}}{\mathrm{K}_{\mathrm{f}}}$ & $\mathrm{Subscripts}$ & \\
$p$ & pressure $\left(\mathrm{N} / \mathrm{m}^{2}\right)$ & & bulk \\
$R e$ & Reynolds number $4 m / \pi d \mu$ & $b$ & fluid \\
$T$ & temperature $\left({ }^{\mathrm{O}} \mathrm{C}\right)$ & $f$ & inner surface \\
$T_{p c}$ & pseudo-critical temperature $\left({ }^{\mathrm{O}} \mathrm{C}\right)$ & $i$ & mean \\
& & $m$ & \\
\hline
\end{tabular}

\section{Author contribution}

All authors contributed equally to this work.

\section{Funding}

This research received no specific grant from any funding agency in the public, commercial, or not-for-profit sectors.

\section{Data availability statement}

The data that support the findings of this study are available on request from the corresponding author.

\section{Conflicts of interest}

The authors declare that there is no conflict of interest.

\section{Reference}

[1] Z. Ajrat, A. A. Jaddoa, B. R. Timur, and M.F. Gumerov, Synthesis of the palladium catalyst with the supercritical co2impregnation method realized in the static mode, Int. j. anal. mass spectrom. chromatogr., 2 (2014) $113-122$. https://doi.org/10.4236/ijamsc.2014.24010

[2] A. A. Jaddoa, B. T. Bilalov, M.F.Gumerov , R. Farizan, B. L.Neindre B., Regeneration of Nickel-Molybdenum Catalysts DN-3531 and Criterion 514 Used in Kerosene and Gas Oil Hydrotreating by Supercritical Carbon Dioxide Extraction, Int. j. anal. mass spectrom. chromatogr., 3 (2015) 37-46. https://doi.org/10.4236/ijamsc.2015.33005

[3] A. A. Jaddoa, T.R. Bilalov, F.M. Gumerov, F.R. Gabitov, Z.I. Zaripov, R.S. Yarullin, A.A. Pimerzin, P.A. Nikul'shin, Supercritical fluid CO2-extraction regeneration of nickel-molybdenum catalyst for hydrotreatment, Catalysis in Industry, 9 (2017) 31-38. https://doi.org/10.1134/S2070050417010020

[4] A. A. Jaddoa, A.A. Zakharov, T.R. Bilalov, R.R. Nakipov, I.R. Gabitov, Z.I. Zaripov, and F.M. Gumerov, Some thermodynamic processes of anthracite-carbon dioxide mixture in supercritical fluid state, Russ. J. Phys. Chem. B.10 (2016) 1180-1190. https://doi.org/10.1134/S1990793116080029

[5] T.R. Bilalov, A.A. Zakharov, A. A. Jaddoa, F.M. Gumerov, and B. Le, Neindre, Treatment of different types of cotton fabrics by ammonium palmitate in a supercritical CO2 environment, J. Supercrit Fluids., 130 (2017) 47-55. https://doi.org/10.1016/j.supflu.2017.07.036

[6] A. A. Jaddoa, Convection heat transfer performance for the Scf-CO2 media in mini-tube with fins experimentally, J. Eng. Sci. Technol., 16 (2021) 3407-3420. 
[7] P.X. Jian, Y.J. Xu, J. Lv , S. He, J.D. Jackson, Experimental investigation of convection heat transfer of CO2 at supercritical pressures in vertical mini-tubes and in porous media, Appl. Therm. Eng. 24 (2004) 1255-1270. https://doi.org/10.1016/j.applthermaleng.2003.12.024.

[8] S.M. Liao and T.S. Zhao, An experimental investigation of convection heat transfers to supercritical carbon dioxide in miniature tubes, Int. J. Heat Mass Transf. 45 (2002) 5025-5034. https://doi.org/10.1016/S0017-9310(02)00206-5.

[9] S.H. Yoon, J.H. Kim, Y.W. Hwang, Heat transfer and pressure drop characteristics during the in-tube cooling process of carbon dioxide in the supercritical region, Int. J. Refrig. $26 \quad$ (2003) 857-864. $\quad$ https://doi.org/10.1016/S0140$\underline{7007(03) 00096-3}$

[10] J.H. Hsu, C.S. Tan, Separation of ethanol from aqueous solution by a method incorporating supercritical CO2 with reverse osmosis, J. Membr. Sci. 81 (1993) 273-285. https://doi.org/10.1016/0376-7388(93)85179-Z

[11] S.V. Dzyuba, R.A. Bartsch, Recent advances in applications of room temperature ionic liquid/supercritical CO2 systems, Angew. Chem. Int. Ed. 42 (2003) 148-150. https://doi.org/10.1002/anie.200390070

[12] K. Khosravi-Darani, E. Vasheghani-Farahani, Application of supercritical fluid extraction in biotechnology, Crit. Rev. Biotechnol. 25 (2005) 231-242. https://doi.org/10.1080/07388550500354841

[13] H. Taher, S. Al-Zuhair, A. Al-Marzouqi, Y. Haik, M. Farid, Growth of microalgae using $\mathrm{CO}_{2}$ enriched air for biodiesel production in supercritical $\mathrm{CO}_{2}$, Renewable Energy 82 (2015) 61-70. https://doi.org/10.1016/j.renene.2014.08.013

[14] C. Song, Global challenges and strategies for control, conversion and utilization of CO2 for sustainable development involving energy, catalysis, adsorption and chemical processing, Catal. Today 115 (2006) 2-32. https://doi.org/10.1016/j.cattod.2006.02.029.

[15] L. F. Cabeza, A. Gracia, A. InésFernández, M. M. Farid, Supercritical $\mathrm{CO}_{2}$ as heat transfer fluid: A review, Appl. Therm. Eng., 125 (2017) 799-810. https://doi.org/10.1016/j.applthermaleng.2017.07.049

[16] K. Nasr, S. Ramadhyani, R. Viskanta, An experimental investigation on forced convection heat transfer from a cylinder embedded in a packed bed, J. Heat Transfer, 116 (1994) 73-80. https://doi.org/10.1115/1.2910886

[17] U. A. Jeigarnik, F. P. Ivanov, N. P. Ikranikov, Experimental data on heat transfer and hydraulic resistance in unregulated porous structures, Teploenergetika, (1991) 33-38.

[18] V. V. Haritonov, U. N. Kice!eva, V. V. Atamanov, U. A. Jeigarnik, F. P. Ivanov, Generalization of the Results on Heat Transfer Intensification in Channels with Porous Insertion (in Russian), Teplofizika Vys. Temp., 32 (1994) $433-440$.

[19] F. C. Lai, F. A. Kulacki, The effect of variable viscosity on convective heat transfer along a vertical surface in a saturated porous medium, Int. J. Heat Mass Transfer, 33 (1990) 1028-1031. https://doi.org/10.1016/0017-9310(90)90084-8

[20] P. X. Jiang, B. X. Wang, Z. P. Ren, A Numerical Investigation of Mixed Convection in a Vertical Porous Annulus, 10th Int. Heat Transfer Conf., Brighton, UK, 5 (1990) 1028-1031.

[21] V.S. Grigoriev, A.F. Polyakov, S.V. Rosnovsky, Heat transfer of fluids at super-critical pressures with variable heat flux along length in tubes Teplofiz. Vys. Temp. 15 (1977) 1241-1247.

[22] E.A. Krasnoshchekov, V.S. Protopopov, Experimental study of heat exchange in carbon dioxide in the supercritical range at high temperature drops, Teplofiz. Vys. Temp. 4 (1966) 389-398.

[23] V.S. Protopopov, Generalized correlations for local heat transfer coefficient for turbulent flow of water and carbon dioxide at super-critical pressure in uniformed heated tubes, Teplofiz. Vys. Temp. 15 (1977) 815-821.

[24] R. B. Gupta, J.J. Shim, Solubility in supercritical carbon dioxide, book, New York, Taylar and Francis Group, ISBN 10:08493-4240-6, 2017. https://doi.org/10.1201/9781420005998. 